\title{
The Drosophila $\beta$-Amyloid Precursor Protein Homolog Promotes Synapse Differentiation at the Neuromuscular Junction
}

\author{
Laura Torroja, ${ }^{1}$ Mary Packard, ${ }^{2}$ Michael Gorczyca, ${ }^{2}$ Kalpana White, ${ }^{1}$ and Vivian Budnik ${ }^{2}$ \\ ${ }^{1}$ Department of Biology, Brandeis University, Waltham, Massachusetts 02454, and 2Department of Biology, University of \\ Massachusetts, Amherst, Massachusetts 01003
}

Although abnormal processing of $\beta$-amyloid precursor protein (APP) has been implicated in the pathogenic cascade leading to Alzheimer's disease, the normal function of this protein is poorly understood. To gain insight into APP function, we used a molecular-genetic approach to manipulate the structure and levels of the Drosophila APP homolog APPL. Wild-type and mutant forms of APPL were expressed in motoneurons to determine the effect of APPL at the neuromuscular junction (NMJ). We show that APPL was transported to motor axons and that its overexpression caused a dramatic increase in synaptic bouton number and changes in synapse structure. In an App/ null mutant, a decrease in the number of boutons was found. Examination of NMJs in larvae overexpressing APPL revealed that the extra boutons had normal synaptic compo- nents and thus were likely to form functional synaptic contacts. Deletion analysis demonstrated that APPL sequences responsible for synaptic alteration reside in the cytoplasmic domain, at the internalization sequence GYENPTY and a putative $\mathrm{G}_{\mathrm{o}^{-}}$ protein binding site. To determine the likely mechanisms underlying APPL-dependent synapse formation, hyperexcitable mutants, which also alter synaptic growth at the NMJ, were examined. These mutants with elevated neuronal activity changed the distribution of APPL at synapses and partially suppressed APPL-dependent synapse formation. We propose a model by which APPL, in conjunction with activity-dependent mechanisms, regulates synaptic structure and number.

Key words: APPL; APP; Alzheimer's disease; $\mathrm{G}_{\mathrm{o}}$-protein; internalization; activity-dependent synapse formation; UAS/Gal4
The Drosophila $\beta$-amyloid precursor protein (APP) homolog APPL (Rosen et al., 1989) is a pan-neural protein belonging to the conserved APP family. This family includes APP and APLP1/2 in mammals (Kang et al., 1987; Wasco et al., 1992, 1993), apl-1 in nematodes (Daigle and Li, 1993), and $\mathrm{APP}_{747}$ in Xenopus (Okado and Okamoto, 1992). APP is synthesized as a transmembrane glycoprotein composed of extracellular, transmembrane, and cytoplasmic domains (Kang et al., 1987; Luo et al., 1990; Wasco et al., 1993). APPs undergo proteolytic cleavage, releasing the ectodomain (Weidemann et al., 1989; Luo et al., 1990; Sisodia, 1994; Slunt et al., 1994). Homology among APP members is paralleled by their ability to functionally substitute for each other: transgenes encoding Drosophila APPL or a human neural APP both rescue behavioral defects of $A p p l$ null flies (Luo et al., 1992).

Expression studies reveal a relationship between stages of APP synthesis and neurite outgrowth and synaptogenesis. In mammals, transmembrane APP is associated with elongating axons, whereas secreted APP is correlated with synaptogenesis (Loffler and Huber, 1992; Moya et al., 1994). In Drosophila, APPL is

Received April 16, 1999; revised June 14, 1999; accepted June 28, 1999.

This work was supported by National Institutes of Health Grants RO1 NS30072 and KO4 NS01786 to V.B. and GM33205 to K.W. L.T. was supported on a postdoctoral fellowship from the Ministry of Education of Spain and a grant from G. Bursak. We thank Drs. E. Buchner, H. Bellen, and K. E. Zinsmaier for their generous gifts of antibodies and Dr. U. Thomas for critical reading of this manuscript and helpful discussions. We also thank the reviewers for their thorough review and helpful comments. We thank Mutuhi Mugo for her assistance with the dissections and the Electron Microscopy Facility and Biology Computer Resource Center at the University of Massachusetts.

L.T. and M.P. contributed equally to this work.

Correspondence should be addressed to Vivian Budnik, Department of Biology, Morrill Science Center, University of Massachusetts, Amherst, MA 01003.

Copyright (C) 1999 Society for Neuroscience $0270-6474 / 99 / 197793-11 \$ 05.00 / 0$ enriched in growing axons and areas of synapse formation (Torroja et al., 1996).

The effects of APP on neuronal development and function have been extensively studied because of their implication in Alzheimer's disease (for review, see Mattson, 1997; Small, 1998). APP exhibits neurite outgrowth-promoting activities in vitro through interactions with the extracellular matrix (Koo et al., 1993; Small et al., 1994) and changes in intracellular calcium (Mattson, 1994). Experiments with neuronal cultures suggest that secreted APP modulates excitability via $\mathrm{Ca}^{2+}$-dependent $\mathrm{K}^{+}$ channels (Furukawa et al., 1996) and NMDA receptor activity (Furukawa and Mattson, 1998).

In vivo evidence supports a role for APP in synapse formation, maintenance, and plasticity. APP administration increases synaptic density and memory retention (Roch et al., 1994), and exposure of hippocampal slices to secreted APP enhances long-term potentiation and modifies the induction of long-term depression (Ishida et al., 1997). APP knock-out mice show impaired learning and memory (Müller et al., 1994; Zheng et al., 1995). However, experiments with APP overexpression are contradictory, demonstrating enhancement of synaptic density (Mucke et al., 1994) or Alzheimer's-like pathology and lack of synaptotrophic effects (Higgins et al., 1993; Masliah et al., 1995). Much of this controversial evidence may arise from the inability, in these systems, to analyze APP function at the level of single synapses.

To investigate the role of APP at single, identified synapses, we used the Drosophila neuromuscular junction (NMJ). We show that APPL overexpression in motoneurons results in a dramatic increase in the number of synaptic boutons. Conversely, NMJs of Appl null larvae exhibit a significant decrease in synaptic bouton number. The synapse-promoting function required a conserved internalization sequence and a putative $G_{o}$ binding site at the 
cytoplasmic domain. This function was partially suppressed by mutations with increased excitability, which by themselves regulate synapse growth (Budnik et al., 1990) and APPL expression at the NMJ.

\section{MATERIALS AND METHODS}

Fly strains. Flies were reared in standard cornmeal-molasses medium and maintained at room temperature, unless otherwise specified. To drive expression of Appl transgenes in motoneurons, the Gal4 enhancer traps c155 (Lin and Goodman, 1994) and P[Gal4w $\left.{ }^{+}\right]$C164 (J. Sharpe, M. Packard, and V. Budnik, unpublished observations) and the transgene Appl-Gal4 (Torroja et al., 1999) were used. We also used a fly strain carrying the UAS-LacZ reporter gene (Brand and Perrimon, 1993). The following mutant stocks were used: $\mathrm{Appl}^{d}$, a null mutation of the Appl gene, $e^{4 g^{4 P M}} S h^{5}$, and $\mathrm{eag}^{1} S h^{K S 133}$ (Budnik et al., 1990).

DNA constructs for germ line transformation. The pUAST vector (Brand and Perrimon, 1993) was used as the germ line transformation vector. Generation of cDNAs $\mathrm{Appl}^{+}, \mathrm{Appl}^{s}$, and $\mathrm{Appl}^{s d}$ has been described previously (Luo et al., 1992; Torroja et al., 1996). To generate APPL $^{\text {sd }}$ cytoplasmic deletions $\Delta \mathrm{C}$ and $\Delta \mathrm{Cg}$, oligo-directed mutagenesis was performed using cDNA $\mathrm{Appl}^{\text {sd }}$ in Bluescript $\mathrm{SK}^{+}$as the template, and oligos tggccaaatggcgataagcttacatcgcgctcg for UAS-App ${ }^{\text {sd } \Delta C}$ and cgctcgccgcacgcccagacacaccatcccattgtg for $A p p l^{s d \Delta C g}$. For $A p p l^{s d \Delta C I}$, the internal SalI fragment of $A_{p p l}{ }^{\Delta C I}$ (Luo, 1992) was replaced by the SalI fragment of $A p p l^{s d}$. Appl $l^{s d \Delta E 1}$ and $A p p l^{s d \Delta E 2}$ are internal deletions of the StuI and the StyI restriction fragments, respectively. All Appl cDNAs were cloned into the EcoRI site of pUAST, and orientation was confirmed by restriction analysis. To generate UAS- $A P P_{695}, \mathrm{SK}^{+}-A P P_{695}$ (Kang et al., 1987) was digested with SalI and $X b a I$, and the insert containing the entire $A P P_{695}$ coding region was cloned into pUAST digested with $X h o \mathrm{I}$ and $X b a \mathrm{I}$.

$P$ element-mediated germ line transformation was performed according to described methods (Spradling and Rubin, 1982). $D f(1) w$ flies were the parental strain for all germ line transformations. Flies bearing autosomal transgenes were used for the analysis.

Protein extraction, electrophoresis, and immunoblot. Frozen heads were extracted in homogenization buffer (50 mM Tris-HCl, pH 8.0, $150 \mathrm{~mm}$ $\mathrm{NaCl}, 1 \mathrm{~mm}$ EGTA, $1.5 \mathrm{mM} \mathrm{MgCl}_{2}$, and $1 \%$ Triton X-100) with proteinase inhibitors. The amount of protein was measured using Bio-Rad (Hercules, CA) Protein Assay reagent, and the same amount of total protein, corresponding to $\sim 1.5$ heads, was loaded for each genotype. Electrophoresis and electrotransfer were performed as described previously (Torroja et al., 1996). Immunoreaction with antibody was visualized using LumiGLO Chemoluminescent Substrate kit (Kirkegaard \& Perry Laboratories, Gaithersburg, MD) according to the manufacturer's specifications. After exposure, the autoradiograph was scanned using the Bio-Rad Gel Doc 1000, and the intensity of the bands was quantified using ImageQuant software (Molecular Dynamics, Sunnyvale, CA). Rabbit polyclonal anti-APPL antibody Ab952 (Torroja et al., 1996) was used at 1:500 dilution to detect all APPL protein forms containing the entire extracellular domain; this antibody detects both the transmembrane and soluble forms of APPL. A polyclonal rabbit antibody against the cytodomain of APP (\#332) (Buxbaum et al., 1990) was used to detect APPL transmembrane forms containing the entire cytoplasmic domain; this antibody cross-reacts with the APPL cytodomain and does not recognize any other proteins in flies lacking APPL $\left(A p p l^{d}\right)$.

Immunocytochemistry and quantification of synapse number. Immunocytochemistry procedures and confocal image acquisition and analysis were performed as reported by Budnik et al. (1996). To determine the number of synapses, body wall muscle preparations were labeled with a presynaptic marker (anti-HRP), and boutons were counted at muscles 6 and 7 of abdominal segment 3 . Three different parameters were measured: the total number of synaptic boutons, the percentage of satellites (satellites $\times 100 /$ total boutons), and the number of "parent" boutons (total boutons - satellites) (see description of satellites in Results). For the expression of APPL variants using the UAS/Gal4 system, crosses and rearing of larvae were performed at $30^{\circ} \mathrm{C}$ to maximize expression of Gal4-driven transgenic APPL. Controls at this temperature were also performed for wild type, the homozygous Gal4 strain, the homozygous strain carrying the Appl transgene, and the Gal4/UAS-LacZ heterozygote. The following antibodies were also used to label synaptic terminals: anti-APPL Ab952 (Torroja et al., 1996) was used at a 1:500 dilution; anti-Discs-large (DLG) at a 1:250 dilution (Woods and Bryant, 1991; Lahey et al., 1994); anti-synapsin (gift from E. Buchner, Universitaet
Wuerzburg) (Klagges et al., 1996); anti- $\beta$-galactosidase at a 1:1000 dilution (Cappel, West Chester, PA); anti-synaptotagmin at a 1:500 dilution (gift from H. Bellen, Baylor College of Medicine) (Littleton et al., 1993); and anti-cysteine string protein (CSP) at a 1:250 dilution (gift from K. E. Zinsmaier, University of Pennsylvania School of Medicine) (Zinsmaier et al., 1990). Secondary antibodies were used at 1:200 dilution.

Transmission electron microscopy. Transmission electron microscopy analysis was essentially performed as described by Jia et al. (1993), except that $1 \mathrm{~mm} \mathrm{Mg}^{2+}$ was added to the Trump's fixative, which appeared to improve the fixation of internal bouton structures. Transverse ultrathin serial sections $(70-90 \mathrm{~nm})$ were cut from ventral longitudinal muscles 6 and 7 at abdominal segments A2 and A3. Three wild-type (21 boutons), three $\mathrm{APPL}^{\text {sd }}$ (17 boutons), and three $\mathrm{APPL}^{+}$(13 boutons) samples were used for this study. In all cases, boutons were analyzed from photographs taken at $15,000-30,000 \times$ magnification, corresponding to the bouton midline (Budnik et al., 1996). Morphometric analysis (number of active zones) was performed as described by Budnik et al. (1996) using larvae expressing APPL ${ }^{\text {sd }}$.

\section{RESULTS}

\section{APPL is transported to synaptic boutons at the NMJ but it is not required for NMJ formation}

We have shown previously that APPL is found at developing central synapses, such as the synaptic layers of the pupal optic lobes (Torroja et al., 1996). However, not all neuropil regions display APPL immunoreactivity, indicating that APPL is present differentially at synapses. To determine whether APPL is transported to motoneuron synapses, we used antibodies directed against the APPL ectodomain (Torroja et al., 1996) to label larval body wall muscle preparations. We found that APPL was consistently distributed in a punctate pattern within the abdominal nerves, down to the point of contact with body wall muscles, consistent with axonal transport of APPL (Fig. 1A1,A2). NMJs showed very weak APPL signal (Fig. 1A2). No signal was detected in nerves or NMJs of the $A p p l$ null mutant $\left(A p p l^{d}\right)$ larvae, demonstrating that APPL immunoreactivity at nerves and NMJs was specific (Fig. 1B1,B2).

APPL signal at synaptic terminals was enhanced when APPL was overexpressed in the nervous system. Neural APPL overexpression was achieved using the UAS/Gal4 system for targeted gene expression (Brand and Perrimon, 1993). The UAS-Appl ${ }^{+}$ transgene was driven by pan-neural Gal4 drivers c155 (Lin and Goodman, 1994) or Appl-Gal4 (Torroja et al., 1999), or the motoneuron-specific Gal4 driver $\mathrm{P}\left[\mathrm{Gal}_{4 \mathrm{w}}{ }^{+}\right] \mathrm{C} 164$. Expression of APPL and its influence on synapse structure was examined at muscles 6 and 7. These muscles are innervated by two glutamatergic motoneurons that give rise to morphologically and physiologically distinct synaptic boutons [type Ib (big) and type Is (small)] (Atwood et al., 1993; Jia et al., 1993; Kurdyak et al., 1994). At the NMJs of larvae overexpressing $\mathrm{APPL}^{+}$, APPL immunoreactivity was readily evident (Fig. 1C1,C2). APPL signal appeared in a nonhomogenous punctate pattern, primarily inside synaptic boutons (colocalized with anti-HRP as a presynaptic marker) but also outside in the immediate vicinity of synaptic boutons (Fig. 1C1,C2). The APPL immunoreactivity outside the boutons may represent secreted APPL, as overexpressing a secretion-deficient APPL form (APPL ${ }^{\text {sd }}$ ) resulted in APPL immunoreactivity that was more restricted to synaptic boutons (see below). However, the nature of the outside signal was not further investigated.

The presence of APPL in motor axons and their synaptic terminals suggested that it might be involved in synapse development and/or function. We therefore examined NMJs from $\mathrm{Appl}^{d}$ larvae to ascertain the effects of the lack of APPL on synapse 

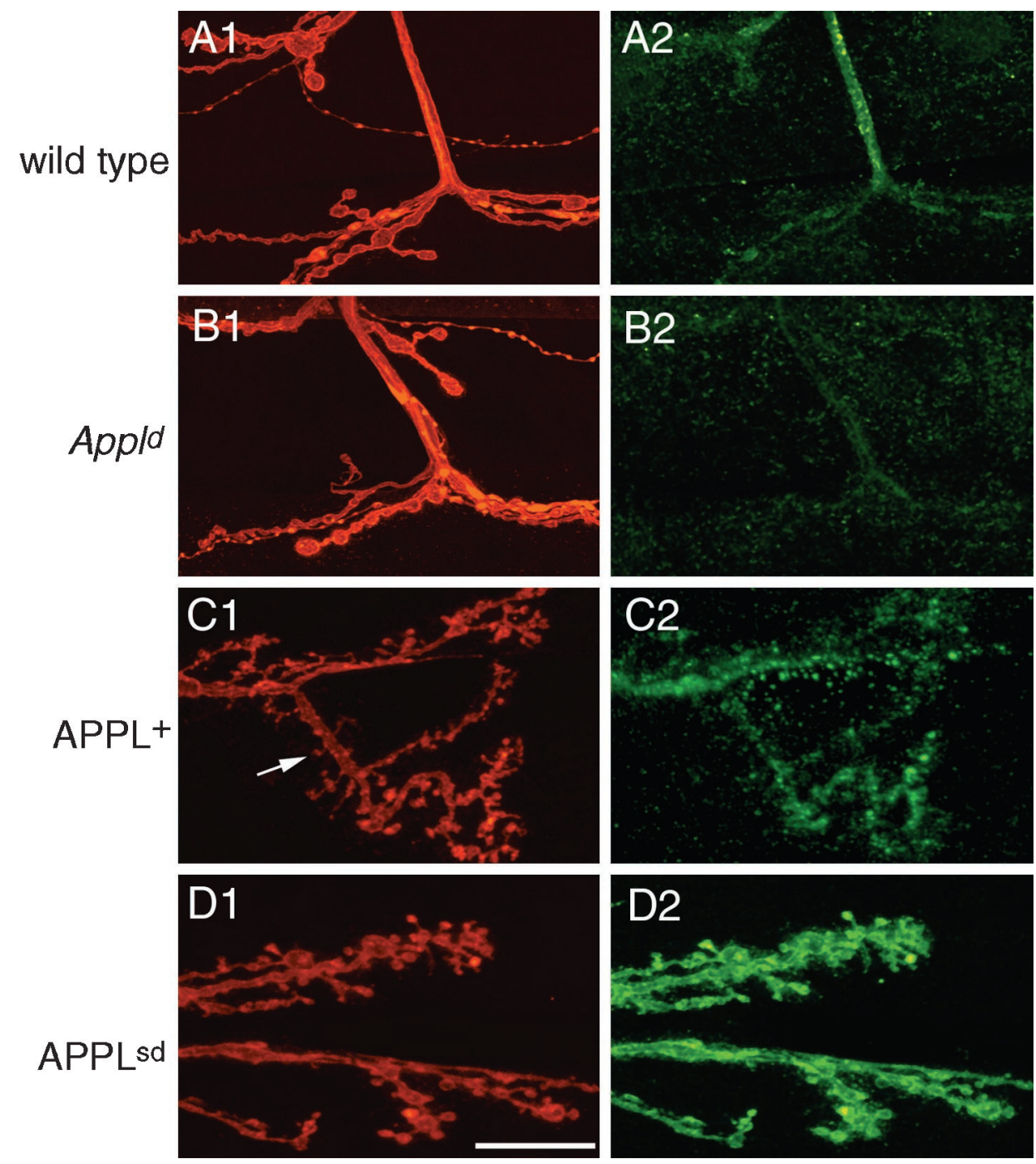

Figure 1. Transport of APPL to motor axons and nerve terminals, and synapse morphology at NMJs with altered APPL levels. A1-D1, Anti-HRP staining of larval NMJs in wild-type muscles 12 and 13 (A1), Appl $^{d}$ mutant muscles 12 and 13 (B1), a larva overexpressing $\mathrm{APPL}^{+}$(muscles 6/7) (C1), and a larva overexpressing APPL $^{\text {sd }}$ (muscles 6/7) (D1). A2-D2, Anti-APPL immunoreactivity in the same samples. Note the presence of bright immunoreactivity at the nerve of the wild type and the weak immunoreactivity at synaptic boutons. This anti-APPL signal is eliminated in the $\mathrm{Appl}^{d}$ mutant. NMJs from larvae overexpressing either $\mathrm{APPL}^{+}$or AP$\mathrm{PL}^{\text {sd }}$ show strong anti-APPL immunoreactivity. In $\mathrm{Appl}^{\mathrm{sd}}$, immunoreactivity is more restricted to boutons, whereas in $\mathrm{APPL}^{+}$ immunoreactivity is not restricted to boutons but is also found well outside boutons (not colocalized with anti-HRP). Arrow points to a satellite budding off from an NMJ process. Scale bar: $A, B, 25 \mu \mathrm{m} ; C, D$, $12 \mu \mathrm{m}$.
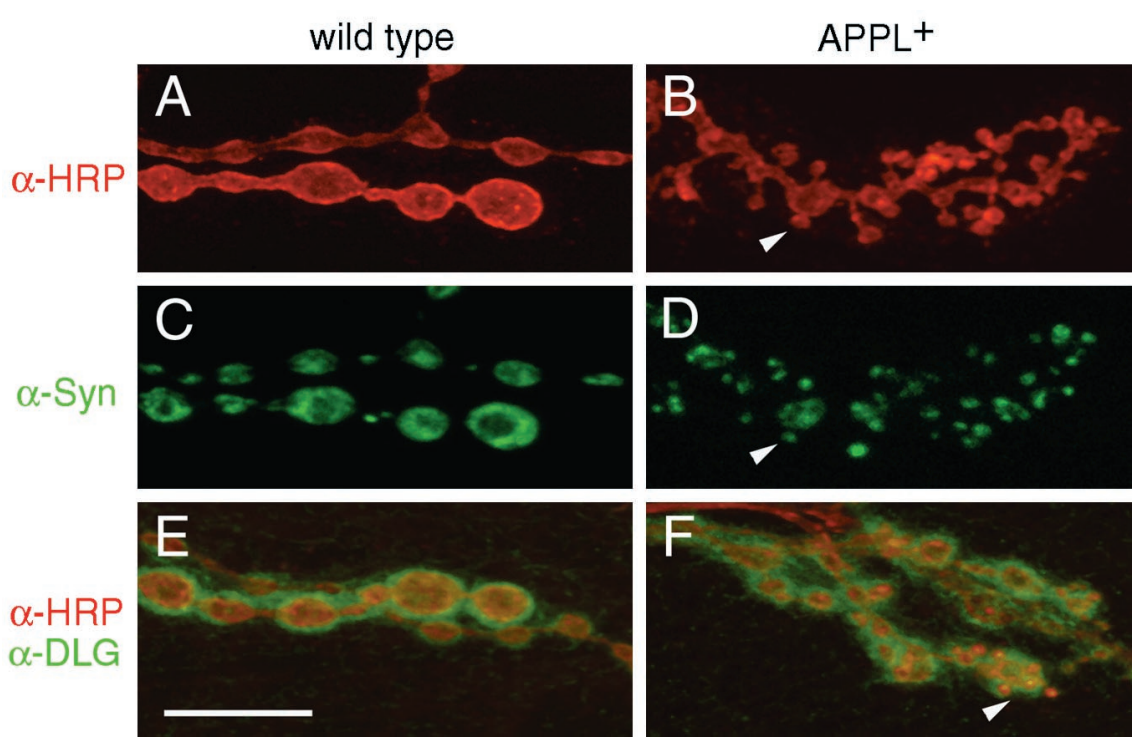

Figure 2. Light microscopic analysis of satellite boutons. $A, B$, Anti-HRP immunoreactivity in a string of synaptic boutons at muscles $6 / 7$ of wild type $(A)$ and a larva overexpressing $\mathrm{APPL}^{+}(B)$. Arrowheads point to a satellite bouton. $C, D$, Anti-synapsin immunoreactivity in wild type $(C)$ (same preparation shown in $A$ ) and a larva overexpressing $\mathrm{APPL}^{+}(D)$ (same preparation shown in $B$ ). Note that each satellite bouton contains synapsin immunoreactivity. $E$, $F$, Anti-HRP (red) and anti-DLG (green) double labeling of NMJs in wild type $(E)$ and a larva overexpressing $\mathrm{APPL}^{+}(F)$. Note that virtually all satellite boutons are surrounded by DLG immunoreactivity. Scale bar, $13 \mu \mathrm{m}$. 

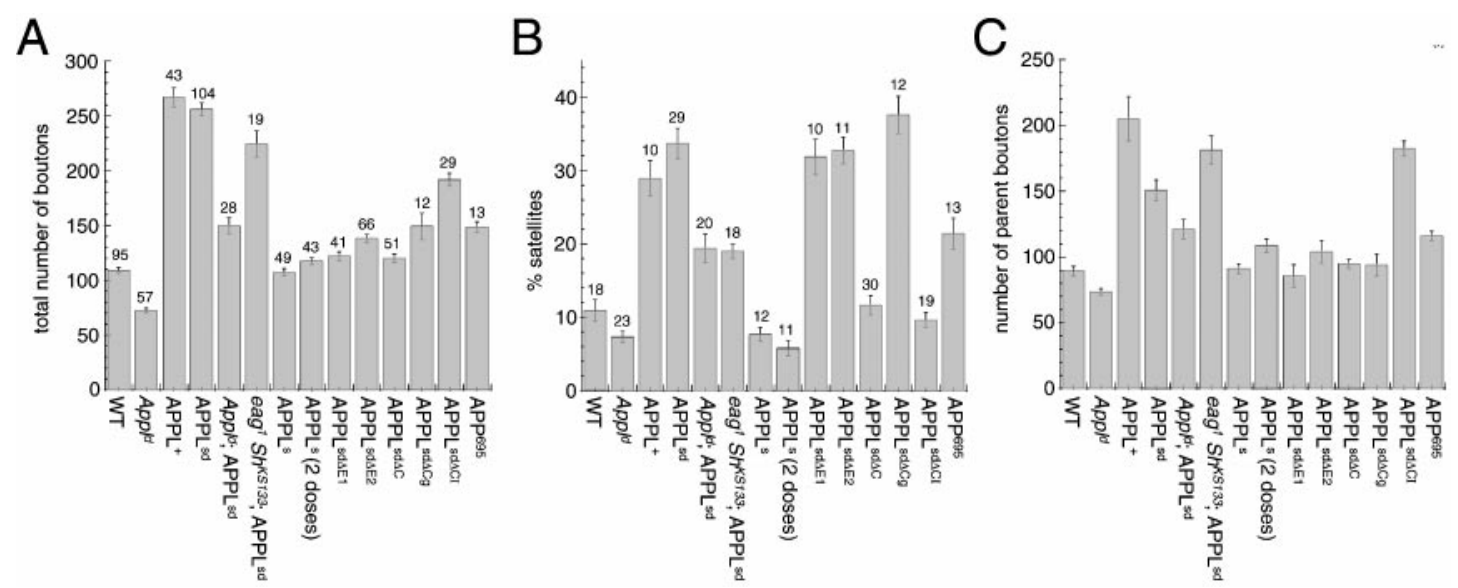

Figure 3. Quantitative analysis of NMJs at muscles 6 and 7 (abdominal segment 3) of wild type and APPL variants expressing normal and altered forms of APPL. $A$, Total number of boutons. $B$, Percentage of satellite boutons relative to total number of boutons (see Results for a definition of satellites). $C$, Number of parent (nonsatellite) boutons. The number of preparations quantified are the same as shown above the bars in $B$.

structure. NMJs from mutant larvae, examined in anti-HRP stained preparations, had a generally normal appearance but contained fewer boutons (Fig. 1B1). We counted the number of synaptic boutons at muscles 6 and 7 of abdominal segment 3 at the light microscopic level (see Materials and Methods) and found that $\mathrm{Appl}^{d}$ showed a significant decrease in the number of synaptic boutons (34\%; $p<0.001)$ compared with wild type (see below).

\section{Overexpression of APPL perturbs NMJ appearance}

When APPL was overexpressed in motoneurons, the increase in APPL signal was accompanied by a change in overall morphology of the NMJ. We were intrigued by these profound structural changes (Fig. 1C1,D1), which included a dramatic increase in the number of synaptic boutons (see below) that resulted largely from numerous small synaptic boutons of abnormal appearance (Figs. $2 B, 3)$. In wild-type NMJs, type I synaptic boutons within a branch resemble a string of beads, with boutons connected to one another by a short neuritic process (Fig. $2 A$ ). In contrast, in larvae overexpressing APPL, many small "satellite" boutons appeared to bud off from a central bouton of normal appearance (Fig. 2B, arrowhead). This phenotype was associated with both type Ib and type Is endings. A fraction of satellite boutons $(\sim 24 \%)$ were also observed budding off from neuronal processes connecting two boutons (Fig. 1C1, arrow).

To determine whether the satellite boutons had normal features of synaptic boutons, we used presynaptic and postsynaptic markers. Analysis of the presynaptic markers synapsin (Fig. $2 C, D$; Klagges et al., 1996), synaptotagmin (data not shown) (Littleton et al., 1993), and CSP (data not shown) (Zinsmaier et al., 1990) revealed that each satellite bouton was immunopositive for these markers. Furthermore, analysis of DLG immunoreactivity, a marker for postsynaptic subsynaptic reticulum (SSR), clearly demonstrated that virtually all satellite boutons were surrounded by SSR (Fig. 2E,F) as is the case with normal boutons (Lahey et al., 1994). Thus, at least some elements of the presynaptic apparatus and postsynaptic SSR are likely to be normal at the satellite synapses.

The fine structure of the satellite boutons was analyzed at the EM level (Fig. 4). As expected from the light microscopic appearance of these NMJs, clusters of boutons were common in APPL ${ }^{+}$ overexpressors, and larger boutons were often surrounded by many small satellite boutons (Fig. $4 B$, asterisks). These satellite boutons appeared to share a common SSR with the central boutons and were frequently observed budding off from a parent bouton (Fig. 4B, arrow). At the presynaptic site, the satellite boutons contained $40 \mathrm{~nm}$ clear synaptic vesicles and mitochondria and displayed one or more T-shaped presynaptic densities (active zones) of normal appearance (Fig. 4B, arrowheads). Quantification of the number of active zones per bouton midline (see Materials and Methods) revealed that boutons from APPL overexpressors and from wild type had a similar number of active zones, $0.62 \pm 0.15$ ( $n=21$ boutons, 3 preparations) in APPL overexpressing larvae versus $1.0 \pm 0.24$ ( $n=17$ boutons, 3 preparations) in wild type. These observations suggest that, although small, satellite boutons have at least several normal type I bouton presynaptic and postsynaptic elements and therefore may form functional synaptic connections.

To quantify the increase of synaptic boutons observed in $\mathrm{APPL}^{+}$overexpressing NMJs, we counted the total number of synaptic boutons (Fig. $3 A$ ), the percentage of satellite boutons (Fig. $3 B$ ), and the number of normal boutons (parent boutons) (Fig. $3 C$ ) at muscles 6 and 7 of abdominal segment 3 at the light microscopic level. For this quantification, boutons were considered to be satellites if they were substantially smaller than normal type I boutons and were connected to a central (parent) bouton (Fig. 1C1,D1). Boutons that had a size and morphology similar to typical satellites but emerged directly from an NMJ process were also considered to be satellites. We found that, in larvae overexpressing $\mathrm{APPL}^{+}$(using C164 as the Gal4 neuronal driver), there was an $\sim 2.5$-fold increase in the total number of boutons $(p<$ $0.001)$, and an approximate threefold increase in the percentage of satellite boutons $(p<0.001)$ compared with wild type. No significant change in the number of synaptic boutons compared with wild type (total number of boutons, $109.6 \pm 2.6 ; n=95$ ) was observed in the control progeny (C164 crossed to UAS-LacZ; total number of boutons, $115.7 \pm 7.3 ; n=19)$. Thus, whereas the lack of APPL in $\mathrm{Appl}^{d}$ mutants leads to a relatively small decrease in the number of synaptic boutons, increasing APPL levels results in a dramatic rise in bouton number. This increase in bouton number resulting from both an increase in satellite boutons and an elevated number of nonsatellite boutons of normal appearance (parent boutons) (Fig. 3). Interestingly, expression of a human APP isoform, $\mathrm{APP}_{695}$, also resulted in a significant but compar- 

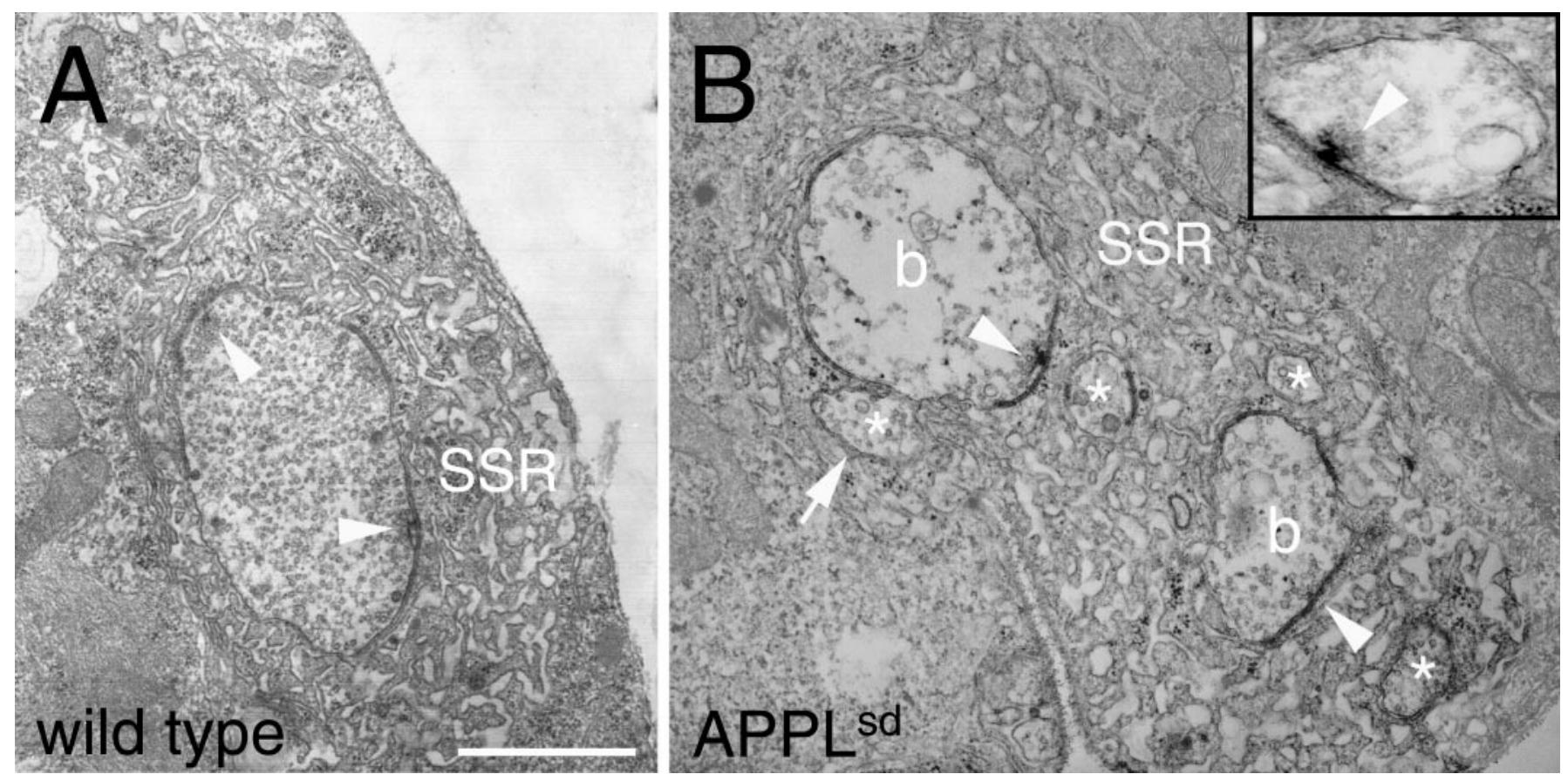

Figure 4. Ultrastructural organization of type I synaptic boutons in a larva overexpressing $\mathrm{APPL}^{+} . A$, Cross-section through a type I synaptic bouton in wild type. $B$, Cross-section through type I boutons and satellite boutons in a larva overexpressing APPL ${ }^{+}$. Note that, in wild type, a single bouton is completely surrounded by the elaborate SSR. In larvae overexpressing APPL ${ }^{+}$, parent boutons $(b)$ and their satellite boutons (asterisks) appear surrounded by a common SSR. Note a satellite bouton budding off from a parent bouton (arrow). Inset shows a view of a satellite bouton containing a presynaptic density. Arrowheads indicate presynaptic densities. Scale bar, $1.2 \mu \mathrm{m}$.

atively smaller increase in the total number of synaptic boutons $(\sim 1.4$ fold; $p<0.001)$ and, particularly, an increase in the percentage of satellite boutons (approximately twofold; $p<0.001$ ) (Fig. 3A,B).

\section{Expression of a transmembrane APPL form mimics APPL $^{+}$-induced NMJ phenotype}

All APP family members are proteolytically processed and can be found as transmembrane and soluble protein forms. Studies demonstrating extensive regulation of the cleavage and release of soluble APP (Gandy and Greengard, 1994; Nitsch et al., 1994) suggest that the two protein forms may play specific roles. To determine whether the transmembrane or soluble APPL isoform can promote satellite formation, we used transgenes that express mutant APPL proteins (Fig. 5A) upon Gal4 activation. UAS$A_{p p l}{ }^{s d}$ transgene encodes a secretion-defective transmembrane form in which APPL lacks the proteolytic cleavage site and consequently is expressed only as a membrane-bound protein. UAS- $A p p l^{s}$ transgene encodes a constitutively secreted form because it lacks the transmembrane and cytoplasmic domains. Analysis of NMJs in larvae expressing APPL ${ }^{\text {sd }}$ or APPL $^{\mathrm{s}}$ demonstrated that APPL ${ }^{\text {sd }}$ expression resulted in a phenotype similar to the phenotype observed in larvae overexpressing $\mathrm{APPL}^{+}$(Figs. $3,6 B$ ), increasing the percentage of satellite boutons (approximately fourfold; $p<0.001$ ) and, to a lesser extent, the number of parent boutons $(\sim 1.7$-fold; $p<0.001)$. In contrast, APPL $^{\mathrm{s}}$ did not significantly differ from wild type with regard to the total number of synaptic boutons or satellites (Fig. $3 A$ ).

The lack of effect seen in APPL ${ }^{\mathrm{s}}$ may be because of differences in the amount of protein expressed. Therefore, we assessed the levels of expression of the different transgenic APPL forms in immunoblots probed with anti-APPL antibodies (Fig. 5B). Im- munoblots of adult head extracts of wild type, $A p p l^{d}$, and transgenic flies expressing different APPL constructs in an $\mathrm{Appl}^{d}$ background revealed that Gal4-driven expression of both $\mathrm{APPL}^{+}$ and $\mathrm{APPL}^{\text {sd }}$ resulted in high levels of protein relative to the endogenous level of APPL (at $30^{\circ} \mathrm{C}$, the amount of $\mathrm{APPL}^{+}$ protein expressed with Appl-Gal4 driver was approximately three times higher than that of endogenous APPL). In contrast, the amount of APPL ${ }^{\mathrm{s}}$ generated from the transgene was only comparable with the amount of endogenous soluble APPL. We suspect that this is attributable to lability of the expressed soluble protein because other Appl mutant constructs expressed with this system all resulted in robust expression. We also attempted to increase the amount of APPL ${ }^{\mathrm{s}}$ by using two doses of the transgene. This manipulation did not alter the total number of boutons but significantly reduced the number of satellites compared with wild type (Fig. 3). In conclusion, both overexpression of $\mathrm{APPL}^{+}$ holoprotein or transmembrane APPL $^{\text {sd }}$ can strongly promote satellite bouton formation, but $\mathrm{APPL}^{\mathrm{s}}$ does not affect the number of total boutons, even after doubling the number of copies of the transgene. However, two doses of $\mathrm{APPL}^{\mathrm{s}}$ decreased the number of satellite boutons (Fig. $3 A$ ).

The results described above suggest that the synaptic boutonpromoting activity associated with APPL overexpression is sensitive to APPL concentration. To test this possibility, we examined the phenotype of NMJs in Appl $^{d}$ larvae that overexpressed $\mathrm{APPL}^{\text {sd }}$ to eliminate wild-type contribution. We found that the increase in the number of synaptic boutons, percentage of satellites, and number of parent boutons was intermediate but significantly different $(p<0.01)$ from wild-type and APPL ${ }^{\text {sd }}$ overexpressing larvae (Fig. 3), supporting a concentration effect of APPL on this activity. 
Figure 5. Mutant APPL proteins. A, Schematic representation of the mutant APPL proteins used in this study. E1 and E2 are the two most conserved regions in the extracellular domain. $C$ is the cleavage site that is deleted in all $\mathrm{APPL}^{\text {sd }}$ forms. TM represents the transmembrane domain. In the cytoplasmic domain, $g$ refers to the putative $\mathrm{G}_{\mathrm{o}}$-binding domain, and $I$ is the internalization signal (see Results). B, Expression of mutant APPL proteins detected in Western blots of adult head total protein extracts. Blots were probed with a polyclonal antibody against the extracellular region of APPL that detects both transmembrane and secreted forms (lanes $1-9$ ), or with a polyclonal antibody against the cytoplasmic internalization signal that detects only the transmembrane form (lanes 10-16). In either case, no protein is observed in $\mathrm{Appl}^{\mathrm{d}}$ heads (lanes 1, 10), and the expected bands are present in wild-type Canton special heads (lanes 2, 11). In lane 2, the intense top band contains transmembrane APPL forms with different post-translational modifications. Directly below, a broad weak band includes soluble APPL proteins with different posttranslational modifications. As expected, this soluble form is not recognized by the antibody against the cytoplasmic domain (lane 11). Lanes 3-9 and 12-16 are extracts from heads of the genotype Appl $^{d}$ Appl-Gal4; UAS$A p p l^{*} /+$ (asterisk indicates any of the deletion constructs) raised at $30^{\circ} \mathrm{C}$ (lanes 3,12 ) or at $20^{\circ} \mathrm{C}$ (lanes $4-9,13-16$ ) in which APPL protein is derived exclusively from the transgene

encoding wild-type $\left(\mathrm{APPL}^{+}\right)$or mutant (APPL ${ }^{\mathrm{s}}$ and APPL $\left.{ }^{\mathrm{sd} \Delta *}\right)$ APPL forms. Appl $^{+}$generates both transmembrane and soluble forms (lanes 3, 4, 12, 13), whereas $\mathrm{Appl}^{\mathrm{s}}$ produces only the soluble forms detected as a weak broad band (lane 5). All Appl ${ }^{\text {sd }}$-derived transgenes generate only transmembrane forms that contain the cytoplasmic domain (compare lane 6 with 14); the bottom band at $\sim 100 \mathrm{kDa}$ most likely corresponds to unglycosylated forms. Molecular weights are expressed in kilodaltons.

\section{The APPL cytoplasmic domain is required to promote synapse formation}

We were interested in finding the domains of APPL that were important for satellite and parent bouton-forming activity. APP family proteins have several conserved domains that were initially recognized from APP and APPL comparison (Rosen et al., 1989) (Fig. 5). Among these are a perfectly conserved internalization sequence in the cytoplasmic domain (GYENPTY) and extracellular regions of high homology E1 and E2. Additionally, in the cytoplasmic domain a $\mathrm{G}_{\mathrm{o}}$-protein binding site, which is conserved in APPL, has been demonstrated (Nishimoto et al., 1993; Okamoto et al., 1995). We used these defined domains as a guide to construct a series of deletion mutants: $\Delta \mathrm{E} 1$, lacking the distal half of E1 and those amino acids (aa) c-terminal to it (85-321 aa); $\Delta \mathrm{E} 2$, lacking $75 \%$ of the distal $\mathrm{E} 2$ and amino acids c-terminal to it (449-740 aa); C100, lacking the entire ectodomain (21-787 aa); $\Delta \mathrm{C}$, lacking the entire cytoplasmic domain (836-886 aa); $\Delta \mathrm{CI}$, lacking the internalization sequence (872-883 aa); and $\Delta \mathrm{Cg}$, lacking the putative $\mathrm{G}_{\mathrm{o}}$-protein binding site (845-855 aa). Appl ${ }^{\text {sd }}$ was chosen rather than $\mathrm{Appl}^{+}$as a parent construct to avoid complications in interpretation that may arise if generated $\mathrm{APPL}^{\mathrm{s}}$ has independent activity. A schematic representation of these constructs is shown in Figure 5A. Because several transformants were obtained with each construct, we selected those lines that showed strong and similar levels of protein expression in immunoblot analysis (Fig. $5 B$ ).

NMJs from larvae expressing the different constructs were double stained with anti-HRP and anti-APPL, and the total number of boutons, the percentage of satellite boutons, and the number of parent boutons were determined. Labeling with antiAPPL antibodies allowed us to determine that, with the exception of C100, all APPL mutant proteins were transported to the NMJs in which they were present at similar levels (data not shown). Because C100 was not transported to the NMJ, quantification of the number of boutons (which was similar to wild type) is not included in the histogram of Figure 5.

The salient observations from quantification of synaptic bouton number in larvae expressing APPL $^{\text {sd }}$-deletion proteins, $\triangle \mathrm{E} 1$, $\Delta \mathrm{E} 2$, and $\Delta \mathrm{C}$, are as follows. (1) APPL ${ }^{\text {sd }}$, further deleted for either of the two extracellular domains ( $\Delta \mathrm{E} 1$ or $\Delta \mathrm{E} 2)$, prevented an increase in the number of parent boutons, yet it still retained satellite bouton-forming activity $(p<0.001)$. (2) In contrast, deletion of the entire cytoplasmic domain of $\mathrm{APPL}^{\text {sd }}(\Delta \mathrm{C})$ completely abolished both the satellite bouton-promoting activity and the increase in the number of parent boutons (Figs. 3B,C, 6C). Thus, the cytoplasmic domain is essential for both the satellite bouton-promoting activity and the formation of extra parent boutons.

To further dissect the likely cytoplasmic domain regions responsible for promoting synapse formation, we also overexpressed smaller deletions in the cytoplasmic domain. Deletion of the putative $\mathrm{G}_{\mathrm{o}}$-protein binding site $(\Delta \mathrm{Cg})$ retained the satellite bouton-promoting capacity $(p<0.001)$, but the formation of extra parent boutons was suppressed (Fig. $3 B, C$ ). Conversely, larvae expressing APPL variants that lack the conserved internalization signal $(\Delta \mathrm{CI})$ had NMJs with a wild-type appearance 


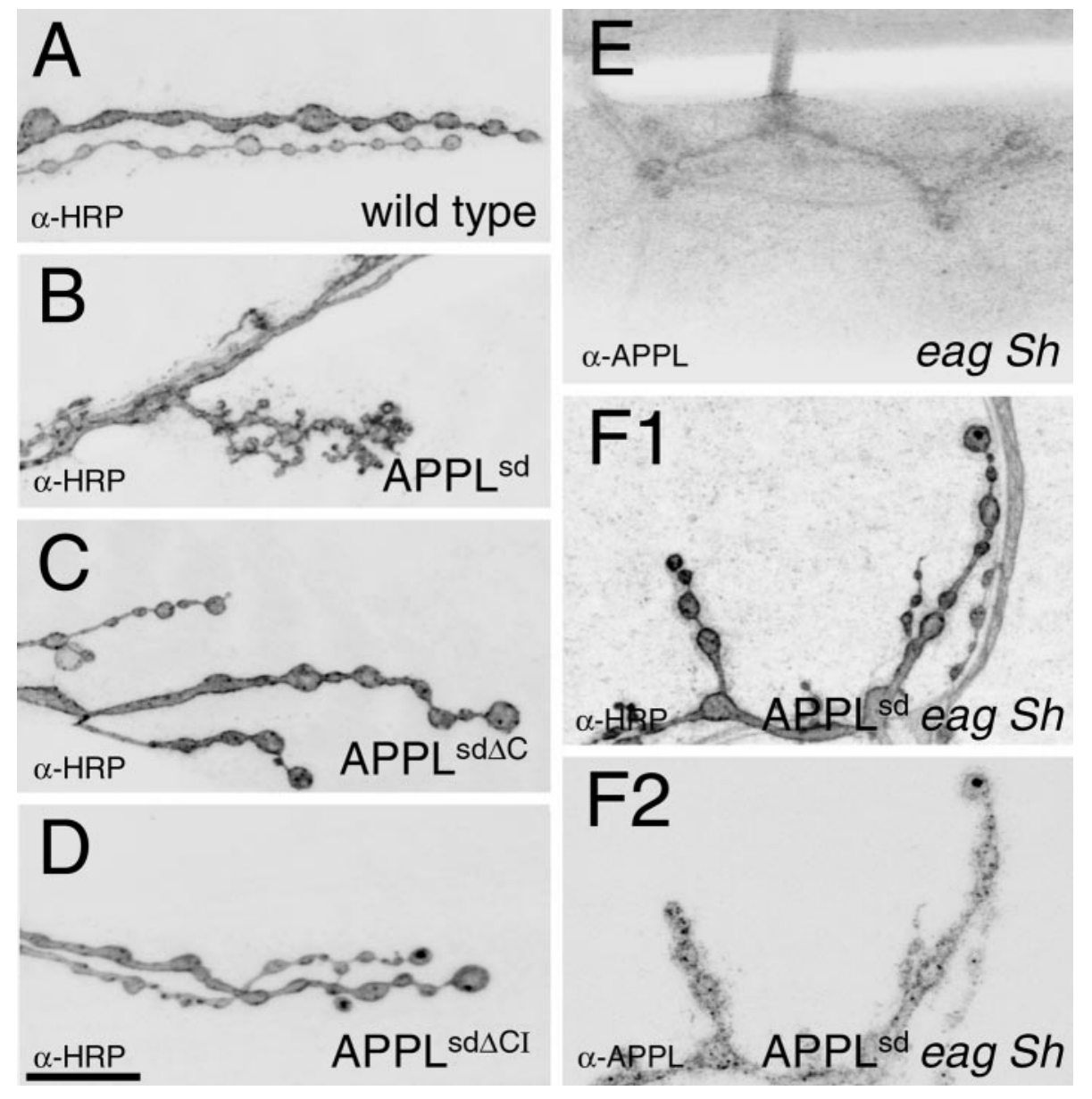

Figure 6. APPL domains required for satellite bouton formation and effect of elevated neuronal activity in APPL expression and satellite bouton formation. $A-D$, Anti-HRP immunoreactivity in wild type $(A)$, an APPL ${ }^{\text {sd }}$ larva $(B)$, an APPL $^{\mathrm{sd} \Delta \mathrm{C}}$ larva $(C)$, and an APPL ${ }^{\mathrm{sd} \Delta \mathrm{CI}}$ larva $(D)$. Note that normal boutons are present in larvae overexpressing the APPL variant lacking the cytoplasmic domain or the conserved internalization sequence. $E$, Expression of APPL in eag Sh mutants. Note that, unlike wild type (Fig. $1 A 2$ ), APPL immunoreactivity at the NMJ of eag Sh mutants is enhanced, and it is associated with the borders of the most distal boutons. F1, NMJs in eag $S h$ mutants expressing APPL ${ }^{\text {sd }}$, showing a decrease in satellite boutons (but see histogram in Fig. 2B). F2, Anti-APPL immunoreactivity in the same preparation as $F 1$. Scale bar: $A-D, F, 12$ $\mu \mathrm{m} ; E, 18 \mu \mathrm{m}$. with regard to the number of satellite boutons (Figs. $3 B, 6 D$ ). Interestingly, however, these larvae still showed a dramatic increase in the number of parent boutons, which translated into an increase in the total number of boutons (Fig. $3 C)(p<0.001)$. Thus, the satellite bouton-promoting activity depends on the presence of the internalization signal, whereas the formation of extra parent boutons depends on the presence of the $G_{o}$-protein binding site and the presence of an intact extracellular domain.

\section{The development of satellite boutons and the expression of APPL may involve activity-dependent mechanisms}

A role for neuronal activity in the development and maintenance of synapses has been documented in many systems (Cline, 1991). Neuronal activity has also been shown to regulate APP metabolism (Allinquant at al., 1994; Nitsch et al., 1994). We wondered whether APPL-mediated regulation of the NMJ growth was induced through neuronal activity. To explore this question, we analyzed the effects of APPL overexpression in the hyperexcitable double mutant eag Sh (Fig. 6). Our goals were to analyze the distribution of endogenous APPL in eag $S h$ mutants and to analyze the NMJ of eag $S h$ mutants overexpressing APPL.

Intriguingly, APPL immunoreactivity in eag Sh differed from wild type. In wild type, APPL signal at synaptic boutons is very low but is observed throughout the NMJ (Fig. 1A2). In contrast, in eag $S h$ mutants, APPL signal was consistently brighter and more concentrated at the most distal bouton(s) of a given NMJ branch (Fig. 6E). In addition, APPL signal appeared more concentrated at the bouton border, suggesting that there might be an increase in plasma membrane-associated APPL. This phenotype was observed in two allelic combinations of eag $S h\left(\mathrm{eag}^{1} \mathrm{Sh}^{K S 133}\right.$ and $e a g^{4 P M} S h^{5}$ ). Western analysis of adult heads revealed no significant difference in the amount of total APPL between wild type and eag $S h$ (data not shown).

Previous studies have revealed that, in eag Sh mutants, both the number of boutons and NMJ branches are increased (Budnik et al., 1990; Jia et al., 1993; Schuster et al., 1996). However, the increase in synaptic boutons in eag $S h$ double mutants differs from that observed in NMJs with APPL overexpression. In NMJs with enhanced APPL levels, the increase in the number of synaptic boutons derives primarily from satellite boutons, whereas in eag $S h$ mutants the increase in the number of synaptic boutons results from an increased elongation of the presynaptic terminals and the formation of new secondary branches (Budnik et al., 1990). In eag Sh larvae overexpressing APPL ${ }^{\text {sd }}$, a reduction in the percentage of satellite boutons was observed when compared with APPL ${ }^{\text {sd }}$ overexpressed in a wild-type background $(p<0.001)$. However, the formation of extra parent boutons was still observed (Fig. $3 B, C)(p<0.001)$. Thus, eag $S h$ changes the pattern of endogenous APPL expression and partially attenuates the satellite bouton-promoting activity elicited by overexpression of APPL.

\section{DISCUSSION}

We used an overexpression approach to determine whether APPL plays a role in the regulation of synapse formation. Overexpression of APPL in motoneurons resulted in morphologically distinct NMJs, characterized by an increase in both parent and 
satellite boutons. To define the APPL domains essential for these effects, we performed an analysis with Appl deletion proteins that were expressed in motoneurons. This demonstrated that a cytoplasmic internalization sequence is essential for satellite bouton formation, whereas a cytoplasmic $G_{o}$-protein binding sequence and extracellular domains are essential in promoting excess parent bouton formation. Furthermore, we observed that, in eag Sh mutants (elevated neuronal activity), APPL overexpressionassociated effects are partially suppressed, and the endogenous pattern of APPL expression at the NMJ is altered. These results indicate that APPL localization and trafficking at the synaptic bouton membrane can be regulated in an activity-dependent manner and may influence synaptic growth.

\section{Regulation of satellite and parent bouton formation by APPL}

The normal appearance of NMJs in larvae lacking APPL in the loss-of-function mutation demonstrates that APPL is not required for synaptogenesis and/or synapse maintenance. However, bouton numbers are reduced, indicating a possible regulatory role. This notion is bolstered by the striking increase in the number of parent and satellite boutons observed when APPL is elevated. Similar to APPL, human neuronal APP also elicited an increase in satellite and parent bouton number. This provides further support for the notion that $\mathrm{APP}_{695}$ and APPL are structurally and functionally conserved.

An increase in bouton number has been observed in several Drosophila mutants that affect synaptic activity, such as eag Sh and dunce (Hannan and Zhong, 1999). In eag Sh, the increase in bouton number appears to derive from longer and more branched neuronal processes containing normal synaptic boutons (Budnik et al., 1990). In contrast, APPL overexpression results in satellite boutons that protrude from a larger parent bouton, although parent bouton number is also increased.

During the postembryonic stage, there is tremendous growth of the NMJ, including elongation and formation of branches, as well as increases in bouton number, number of active zones, and bouton area (Gorczyca et al., 1993; Guan et al., 1996; Schuster et al., 1996). These studies suggest that NMJ expansion involves sprouting and elongation of a process, followed by the differentiation of new terminal boutons. Satellite boutons resulting from APPL overexpression may be caused by increased sprouting and abnormal bouton differentiation.

\section{Functional domains of APPL}

The distribution of different APPL forms in larval brains suggests that the transmembrane and soluble forms play specific roles in Drosophila neurons (Torroja et al., 1996). Indeed, we found that the secretion-deficient APPL form is as effective as wild-type APPL in promoting satellite bouton formation, whereas constitutively secreted APPL has no effect when expressed in one dose and has an effect similar to the Appl null mutant with two doses of the transgene. The observation that two doses of APPL ${ }^{\mathrm{s}}$ result in a reduction in the percentage of satellites may indicate an inhibitory role on the satellite bouton-promoting activities.

Deletion of the APPL cytoplasmic domain abolished both the satellite bouton and parent bouton-promoting activity of APPL. However, these activities can be dissected by smaller deletions of the cytoplasmic and extracellular domains. Deletion of the internalization sequence prevented the formation of satellites but did not prevent the increase in parent boutons. In contrast, deletion of the putative $G_{o}$-protein binding site prevented the increase in the number of parents, but the satellite bouton-promoting activity remained intact. Similar results were found when portions of the extracellular domain (E1 and E2), which may serve to bind a ligand to regulate $\mathrm{G}_{\mathrm{o}}$ function (Okamoto et al., 1995; Brouillet et al., 1999), were deleted.

In vertebrates, the internalization signal is crucial for regulating APP processing and trafficking (Lai et al., 1995; Borg et al., 1998a). It interacts with several proteins, including X11 and Fe65 (Ermekova et al., 1997; Trommsdorff et al., 1998), which may participate in the regulation of APP metabolism (Borg et al., 1998a,b; Sastre et al., 1998). Thus, APPL-dependent satellite bouton formation is likely to involve APPL internalization. Alternatively, or in addition, APPL may signal by interacting with cytoplasmic proteins, leading to the formation of satellite boutons. The low levels of APPL detected in wild-type NMJs suggests that APPL turnover may be high at the plasma membrane, similar to APP turnover in vertebrates (Allinquant et al., 1994; Koo et al., 1996).

Internalization of synaptic proteins plays an important role in the regulation of synaptic growth. For example, the Aplysia cell adhesion molecule ApCaM (Bailey and Kandel, 1993) and its Drosophila homolog Fasciclin II (Schuster et al., 1996) are internalized at synapses in an activity-dependent manner. This promotes synapse growth, presumably by decreasing adhesion between presynaptic and postsynaptic membranes.

Studies in vertebrates show that $\mathrm{APP}_{695}$ behaves as a $\mathrm{G}_{\mathrm{o}}$-linked receptor; its cytoplasmic region binds to $G_{\mathrm{o}}$-protein (Nishimoto et al., 1993; Okamoto et al., 1995). However, whether APP stimulates or downregulates $G_{o}$ is unclear (Brouillet et al., 1999). The observation that deletion of the putative APPL $\mathrm{G}_{\mathrm{o}}$-binding site abolishes the ability of APPL to increase parent bouton number indicates that $G_{0}$ activity may be involved (Fig. 7). This is consistent with observations implicating $G_{o}$ in growth cone motility and synapse plasticity (Goh and Pennefather, 1989; Strittmatter et al., 1994) and with high levels of $\mathrm{G}_{\mathrm{o}}$-protein in developing insect neurites (de Sousa et al., 1989; Wolfgang et al., 1991; Copenhaver et al., 1995).

\section{Is the APPL synaptic bouton-promoting function regulated by neuronal activity?}

Processing and trafficking of APP are known to be affected by neuronal activity (Allinquant et al., 1994; Nitsch et al., 1994). For example, in cortical neurons, the axonal pool of APP holoprotein at the surface was found to be increased after $\mathrm{Ca}^{2+}$ entry (Allinquant et al., 1994). In eag Sh larvae, endogenous APPL signal was consistently increased, especially at the distal-most boutons. Furthermore, when APPL was overexpressed in the hyperexcitable mutant, there was a reduction in satellite bouton number and an increase in parent boutons. This phenotype is similar to the phenotype associated with overexpression of APPL lacking the internalization signal. Thus, deletion of the internalization signal, or high activity, are both likely to increase surface APPL (presumably through a decrease in internalization) and have similar effects on synaptic growth.

\section{APPL-associated function}

We suggest that APPL is involved in synaptic plasticity, because APPL is nonessential for formation and maintenance of synapses but can promote synapse formation and appears to be affected by neuronal activity. NMJ phenotypes resulting from the expression of APPL proteins lacking specific domains suggest that APPL trafficking and APPL-dependent signal transduction are two pro- 

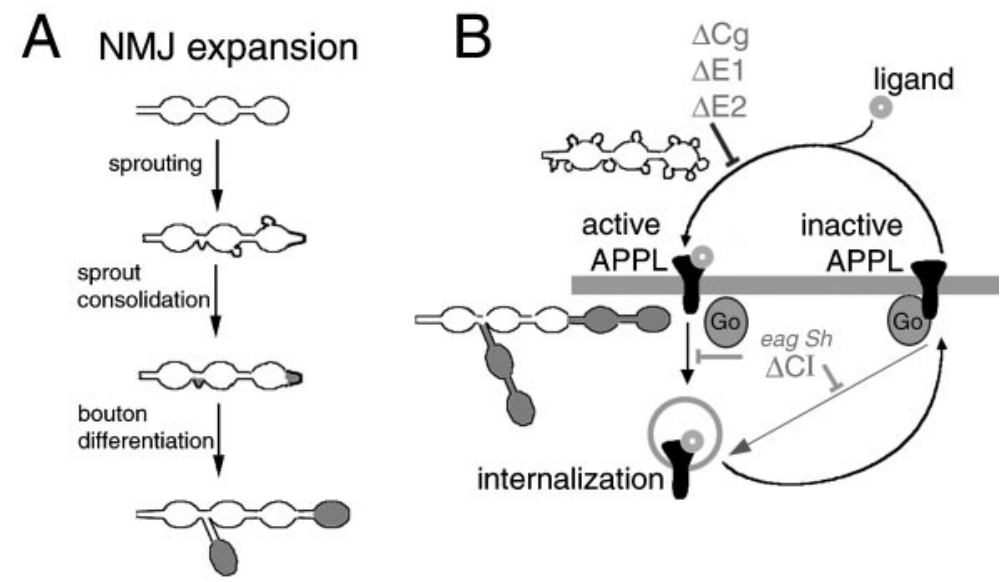

cesses that regulate APPL-induced synaptic growth. The evidence indicates that (1) APP can be rapidly internalized (Koo et al., 1996); (2) processing and trafficking of APPL and APP is affected by activity (Allinquant et al., 1994; this study); and (3) plasma membrane APP, and possibly APPL, behave as $\mathrm{G}_{\mathrm{o}^{-}}$ protein linked receptors (Nishimoto et al., 1993).

We propose that NMJ expansion occurs by two consecutive steps: the formation of sprouts and the consolidation of some of these sprouts into differentiated boutons (see also Zito et al., 1999). Bouton differentiation entails the proper arrangement of presynaptic and postsynaptic components, as well as the enlargement of the sprout to accommodate all the elements required for synaptic transmission. Both sprouting and differentiation are modulated by APPL. We suggest that plasma membrane APPL induces sprouting and that this response is independent of APPL signal transduction. In contrast, bouton differentiation is regulated by APPL signal transduction, which may involve $G_{o}$ (Fig. 7). Internalization of APPL stops both activities. We propose that a satellite bouton is formed when APPL-induced sprouting is initiated, followed by rapid internalization of APPL, thus reducing APPL-dependent signal transduction and, therefore, bouton differentiation. As a result, some degree of differentiation, such as the formation of active zones and transport of vesicles, does occur, but other aspects, such as bouton enlargement, do not.

Several predictions from this model are in line with our findings. For instance, decreasing APPL internalization $(\Delta C I)$ would reduce formation of satellites. A persistent increase in APPL activation, as a result of decreased internalization, is predicted to promote the differentiation of sprouts, thus effectively increasing the number of parent boutons. In contrast, overexpression of APPL variants that are unable to undergo ligand-dependent receptor activation $(\Delta \mathrm{E} 1, \Delta \mathrm{E} 2, \Delta \mathrm{Cg})$ would reduce bouton differentiation, preventing the increase of parents but not of satellites. Full-length APPL (APPL ${ }^{+}$, APPL $^{\text {sd }}$ ) would stimulate both sprouting and differentiation and could be rapidly internalized as in wild type, thus promoting both parent and satellite bouton formation.

Rapid APPL internalization appears to be key to the normally low level of plasma membrane APPL. Increases in plasma membrane-associated APPL result from increased neuronal activity, a factor shown to increase bouton number (Budnik et al., 1990). Strikingly, overexpression of APPL ${ }^{\text {sd }}$ in eag Sh results in reduction of satellites, with a concomitant increase in the number of parent boutons. This further supports the idea that neuronal activity can drive APPL-mediated bouton differentiation.
Figure 7. Role of APPL on NMJ expansion. A, Stages of NMJ expansion during larval development. According to our model, new boutons at expanding NMJs are formed by sprouting, followed by the consolidation of some of the sprouts into undifferentiated boutons, which subsequently differentiate to form a new mature bouton (shaded boutons). $B$, Model of APPL function as a $\mathrm{G}_{\mathrm{o}^{-}}$ coupled receptor. According to this model, the binding of a ligand to APPL activates a transduction cascade that involves $\mathrm{G}_{\mathrm{o}}$-protein. Ligand-bound or unbound APPL is internalized and subsequently recycled to the cell membrane. We propose that surface APPL is involved in sprouting, whereas activation of the transduction cascade is involved in the regulation of bouton differentiation. Deletion of the $\mathrm{G}_{\mathrm{o}}$-protein binding site $(\Delta C g)$ or the conserved extracellular domains $(\Delta E 1, \Delta E 2)$ results in oversprouting with diminished bouton differentiation, leading to satellite boutons. Deletion of the internalization signal $(\Delta C I)$ or elevated levels of electrical activity (eag $S h$ mutants) lead to an increase in surface APPL, resulting in the differentiation of a larger than normal number of sprouts and therefore an increase in the number of parent boutons.

Based on our observations, we conclude that APPL has functional significance for the regulation of synapse formation. Moreover, we have shown that this process involves the APPL domains that are likely to affect APPL signal transduction, suggesting a novel mechanism for the regulation of the size of synaptic arbors.

\section{REFERENCES}

Allinquant B, Moya K, Bouillot C, Prochiantz A (1994) Amyloid precursor protein in cortical neurons: coexistence of two pools differentially distributed in axons and dendrites and association with cytoskeleton. J Neurosci 14:6842-6854.

Atwood HL, Govind CK, Wu C-F (1993) Differential ultrastructure of synaptic terminals on ventral longitudinal abdominal muscles in Drosophila larvae. J Neurobiol 24:1008-1024.

Bailey CH, Kandel ER (1993) Structural changes accompanying memory storage. Annu Rev Physiol 55:397-426.

Borg JP, Yang Y, De Taddeo-Borg M, Margolis B, and Turner RS (1998a) The X11alpha protein slows cellular amyloid precursor protein processing and reduces $\mathrm{A} \beta 40$ and $\mathrm{A} \beta 42$ secretion. J Biol Chem 273:14761-14766.

Borg JP, Straight SW, Kaech SM, de Taddeo-Borg M, Kroon DE, Karnak D, Turner RS, Kim SK, Margolis B (1998b) Identification of an evolutionarily conserved heterotrimeric protein complex involved in protein targeting. J Biol Chem 273:31633-31636.

Brand AH, Perrimon N (1993) Targeted gene expression as a means of altering cell fates and generating dominant phenotypes. Development 118:401-415.

Brouillet E, Trembleau A, Galanaud D, Volovitch M, Bouillot C, Valenza C, Prochiantz A, Allinquant B (1999) The amyloid precursor protein interacts with $G_{o}$ heterotrimeric protein within a cell compartment specialized in signal transduction. J Neurosci 19:1717-1727.

Budnik V, Zhong Y, Wu C-F (1990) Morphological plasticity of motor axon terminals in Drosophila mutants with altered excitability. J Neurosci 10:3754-3768.

Budnik V, Koh Y-H, Guan B, Hartmann B, Haugh C, Woods D, Gorczyca M (1996) Regulation of synapse structure and function by the Drosophila tumor suppressor gene, dlg. Neuron 17:627-640.

Buxbaum JD, Gandy SE, Cicchetti P, Ehrlich ME, Czernik AJ, Fracasso RP, Ramabhadran TV, Unterbeck AJ, Greengard P (1990) Processing of Alzheimer $\beta A 4$ amyloid precursor protein: modulation by agents that regulates protein phosphorylation. Proc Natl Acad Sci USA 87:6003-6006.

Cline HT (1991) Activity-dependent plasticity in the visual systems of frogs and fish. Trends Neurosci 14:104-111.

Copenhaver PF, Horgan AM, Nichols DC, Rasmussen MA (1995) Developmental expression of heterotrimeric $\mathrm{G}$ proteins in the nervous system of Manduca sexta. J Neurobiol 26:461-484.

Daigle I, Li C (1993) apl-1, a Caenorhabditis elegans gene encoding a protein related to the human $\beta$-amyloid protein precursor. Proc Natl Acad Sci USA 90:12045-12049.

de Sousa SM, Hoveland LL, Yarfitz S, Hurley JB (1989) The Drosophila $\mathrm{G}_{\mathrm{o}} \alpha$-like protein gene produces multiple transcripts and is expressed in the nervous system and ovaries. J Biol Chem 264:18544-18551. 
Ermekova KS, Zambrano N, Linn H, Minopoli G, Gertler F, Russo T, Sudol M (1997) The WW domain of neural protein FE65 interacts with proline-rich motifs in Mena, the mammalian homolog of Drosophila enabled. J Biol Chem 272:32869-32877.

Furukawa K, Mattson MP (1998) Secreted amyloid precursor protein alpha selectively suppresses $N$-methyl-D-aspartate currents in hippocampal neurons: involvement of cyclic GMP. Neuroscience 83:429-438.

Furukawa K, Barger SW, Blalock EM, Mattson MP (1996) Activation of $\mathrm{K}^{+}$channels and suppression of neuronal activity by secreted $\beta$-amyloid precursor protein. Nature 379:74-78.

Gandy S, Greengard P (1994) Regulated cleavage of the Alzheimer amyloid precursor protein: molecular and cellular basis. Biochimie 76:300-303.

Goh JW, Pennefather PS (1989) A pertussis toxin-sensitive G protein in hippocampus long-term potentiation. Science 244:980-983.

Gorczyca MG, Augart C, Budnik V (1993) Insulin-like receptor and insulin-like peptide are localized at neuromuscular junctions in Drosophila. J Neurosci 13:3692-3704.

Guan B, Hartmann B, Koh Y-H, Gorczyca M, Budnik V (1996) The Drosophila tumor suppressor gene, $d l g$, is involved in structural plasticity at a glutamatergic synapse. Curr Biol 6:695-706.

Hannan F, Zhong Y (1999) Second messenger systems underlying plasticity at the neuromuscular junction. In: Neuromuscular junctions in Drosophila: international review of neurobiology, Vol 43 (Budnik V, Gramates LS, eds), pp 119-138. San Diego: Academic.

Higgins LS, Catalano R, Quon D, Cordell B (1993) Transgenic mice expressing human $\beta$-APP751, but not mice expressing $\beta$-APP695, display early Alzheimer's disease-like histopathology. Ann NY Acad Sci 695:224-227.

Ishida A, Furukawa K, Keller JN, Mattson MP (1997) Secreted form of $\beta$-amyloid precursor protein shifts the frequency dependency for induction of LTD, and enhances LTP in hippocampal slices. NeuroReport 8:2133-2137.

Jia X, Gorczyca M, Budnik V (1993) Ultrastructure of neuromuscular junctions in Drosophila: comparison of wild type and mutants with increased excitability. J Neurobiol 24:1025-1044.

Kang J, Lemaire HG, Unterbeck A, Salbaum JM, Masters CL, Greschik KH, Multhaun G, Beyreuther K, Muller-Hill B (1987) The precursor of Alzheimer's disease amyloid A4 protein resembles a cell-surface receptor. Nature 325:733-736.

Klagges BR, Heimbeck G, Godenschwege TA, Hofbauer A, Pflugfelder GO, Reifegerste R, Reisch D, Schaupp M, Buchner S, Buchner E (1996) Invertebrate synapsins: a single gene codes for several isoforms in Drosophila. J Neurosci 16:3154-3165.

Koo EH, Park L, Selkoe DJ (1993) Amyloid $\beta$-protein as a substrate interacts with extracellular matrix to promote neurite outgrowth. Proc Natl Acad Sci 90:4748-4752.

Koo EH, Squazzo SL, Selkoe DJ, Koo CH (1996) Trafficking of cellsurface amyloid $\beta$-protein precursor. I. Secretion, endocytosis and recycling as detected by labeled monoclonal antibody. J Cell Sci 109:991-998.

Kurdyak P, Atwood HL, Stewart BA, Wu CF (1994) Differential physiology and morphology of motor axons to ventral longitudinal muscles in larval Drosophila. J Comp Neurol 350:463-472.

Lahey T, Gorczyca M, Jia X, Budnik V (1994) The Drosophila tumor suppressor gene $d l g$ is required for normal synaptic bouton structure. Neuron 13:823-835.

Lai A, Sisodia SS, Trowbridge IS (1995) Characterization of sorting signals in the $\beta$-amyloid precursor protein cytoplasmic domain. J Biol Chem 270:3565-3573.

Lin DM, Goodman CS (1994) Ectopic and increased expression of Fasciclin II alters motoneuron growth cone guidance. Neuron 13:507-523.

Littleton JT, Bellen HJ, Perin MS (1993) Expression of synaptotagmin in Drosophila reveals transport and localization of synaptic vesicles to the synapse. Development 118:1077-1088.

Loffler J, Huber G (1992) $\beta$-amyloid precursor protein isoforms in various rat brain regions and during brain development. J Neurochem 59:1316-1324.

Luo L (1992) Functional analysis of APPL, the Drosophila homologue of human amyloid precursor protein associated with Alzheimer's disease. $\mathrm{PhD}$ thesis, Brandeis University.

Luo L, Martin-Morris LE, White K (1990) Identification, secretion, and neural expression of APPL, a Drosophila protein similar to human amyloid protein precursor. J Neurosci 10:3849-3861.
Luo L, Tully T, White K (1992) Human amyloid precursor protein ameliorates behavioral deficit of flies deleted for Appl gene. Neuron 9:595-605.

Masliah E, Mallory M, Alford N, Mucke L (1995) Abnormal synaptic regeneration in hAPP695 transgenic and ApoE knockout mice. In: Research advances in Alzheimer's disease and related disorders (Iqbal K, Mortimer J, Winblad B, Wisniewsky H, eds), pp 405-414. New York: Wiley.

Mattson MP (1994) Secreted forms of $\beta$-amyloid precursor protein modulate dendrite outgrowth and calcium responses to glutamate in cultured embryonic hippocampal neurons. J Neurobiol 25:439-450.

Mattson MP (1997) Cellular actions of $\beta$-amyloid precursor protein and its soluble and fibrillogenic derivatives. Physiol Rev 77:1081-1132.

Moya KL, Benowitz LI, Schneider E, Allinquant B (1994) The amyloid precursor protein is developmentally regulated and correlated with synaptogenesis. Dev Biol 161:597-603.

Mucke L, Maslaih E, Johnson WB, Ruppe MD, Alford M, Rockenstein EM, Forss-Petter S, Pietropaolo M, Mallory M, Abraham CR (1994) Synaptotrophic effects of human amyloid $\beta$ protein precursors in the cortex of transgenic mice. Brain Res 666:151-167.

Müller U, Cristina N, Li ZW, Wolfer DP, Lipp HP, Rulicke T, Brandner S, Aguzzi A, Weissmann C (1994) Behavioral and anatomical deficits in mice homozygous for a modified $\beta$-amyloid precursor protein gene. Cell 79:755-765.

Nishimoto I, Okamoto T, Maysuura S, Okamoto T, Murayama Y, Ogata E (1993) Alzheimer amyloid protein precursor complexes with brain GTP-binding protein $\mathrm{G}_{\mathrm{o}}$. Nature 362:75-79.

Nitsch RM, Slack BE, Farber SA, Schulz JG, Deng M, Kim C, Borghesani PR, Korver W, Wurtman RJ, Growdon JH (1994) Regulation of proteolytic processing of the amyloid $\beta$-protein precursor of Alzheimer's disease in transfected cell lines and in brain slices. J Neural Transm Suppl 44:21-27.

Okado H, Okamoto H (1992) A Xenopus homologue of the human beta-amyloid precursor protein: developmental regulation of its gene expression. Biochem Biophys Res Commun 189:1561-1568.

Okamoto T, Takeda S, Murayama Y, Ogata E, Nishimoto I (1995) Ligand-dependent $\mathrm{G}$ protein coupling function of amyloid transmembrane precursor. J Biol Chem 270:4205-4208.

Roch JM, Masliah E, Roch-Levecq AC, Sundsmo MP, Otero DA, Veinbergs I, Saitoh T (1994) Increase of synaptic density and memory retention by a peptide representing the trophic domain of the amyloid $\beta /$ A4 protein precursor. Proc Natl Acad Sci USA 91:7450-7454.

Rosen DR, Martin-Morris L, Luo L, White K (1989) A Drosophila gene encoding a protein resembling the human $\beta$-amyloid protein precursor. Proc Natl Acad Sci USA 86:2478-2482.

Sastre M, Turner RS, Levy E (1998) X11 interaction with $\beta$-amyloid precursor protein modulates its cellular stabilization and reduces amyloid $\beta$-protein secretion. J Biol Chem 273:22351-22357.

Schuster CM, Davis GW, Fetter RD, Goodman CS (1996) Genetic dissection of structural and functional components of synaptic plasticity. I. Fasciclin II controls synaptic stabilization and growth. Neuron 17:641-654.

Sisodia SS (1994) Cellular and molecular genetic approaches in Alzheimer's disease. Neurobiol Aging [Suppl] 2:S135-S137.

Slunt HH, Thinakaran G, Koch CV, Lo AC, Tanzi RE, Sisodia SS (1994) Expression of a ubiquitous, cross-reactive homologue of the mouse $\beta$-amyloid precursor protein (APP). J Biol Chem 269:2637-2644.

Small DH (1998) The role of the amyloid protein precursor (APP) in Alzheimer's disease: does the normal function of APP explain the topography of neurodegeneration? Neurochem Res 23:795-806.

Small DH, Nurcombe V, Reed G, Clarris H, Beyreuther K, Masters CL (1994) The role of the extracellular matrix in regulating the function of the amyloid protein precursor of Alzheimer's disease. In: Amyloid protein precursor in development, aging and Alzheimer's disease (Masters CL, Beyreuther K, Trillet M, Christen Y, eds), pp 65-75. Berlin: Springer.

Spradling AC, Rubin GM (1982) Transposition of cloned P elements into Drosophila germ line chromosomes. Science 218:341-347.

Strittmatter SM, Fishman MC, Zhu XP (1994) Activated mutants of the $\alpha$ subunit of $\mathrm{G}(\mathrm{o})$ promote an increased number of neurites per cell. J Neurosci 14:2327-2338.

Torroja L, Luo L, White K (1996) APPL, the Drosophila member of the APP-family, exhibits differential trafficking and processing in CNS neurons. J Neurosci 16:4638-4650. 
Torroja L, Chu H, Kotovsky I, White K (1999) Neuronal overexpression of APPL, the Drosophila homologue of the amyloid precursor protein (APP), disrupts axonal transport. Curr Biol 9:489-492.

Trommsdorff M, Borg JP, Margolis B, Herz J (1998) Interaction of cytosolic adaptor proteins with neuronal apolipoprotein $\mathrm{E}$ receptors and the amyloid precursor protein. J Biol Chem 273:33556-33560.

Wasco W, Bupp K, Magendantz M, Gusella JF, Tanzi RE, Solomon F (1992) Identification of a mouse brain cDNA that encodes a protein related to the Alzheimer's disease-associated amyloid $\beta$ protein precursor. Proc Natl Acad Sci USA 89:10758-10762.

Wasco W, Gurubhagavatula S, Paradis MD, Romano DM, Sisodia SS, Hyman BT, Neve RL, Tanzi RE (1993) Isolation and characterization of APLP2 encoding a homologue of the Alzheimer's associated amyloid $\beta$ protein precursor. Nat Genet 5:95-100.

Weidemann A, Konig G, Bunke D, Fischer P, Salbaum JM, Masters CL, Beyreuther K (1989) Identification, biogenesis, and localization of precursors of Alzheimer's disease A4 amyloid protein. Cell 57:115-126.
Wolfgang WJ, Quan F, Goldsmith P, Unson C, Spiegel A, Forte M (1991) Restricted spatial and temporal expression of $\mathrm{G}$ protein $\alpha$ subunits during Drosophila embryogenesis. Development 113:527-538.

Woods DF, Bryant PJ (1991) The discs-large tumor suppressor gene of Drosophila encodes a guanylate kinase homolog localized at septate junctions. Cell 66:451-464.

Zheng H, Jiang M, Trumbauer ME, Sirinathsinghji DJ, Hopkins R, Smith DW, Heavens RP, Dawson GR, Boyce S, Conner MW, Stevens KA, Slunt HH, Sisodia SS, Chen HY, Van der Ploeg LHT (1995) $\beta$-amyloid precursor protein-deficient mice show reactive gliosis and decreased locomotor activity. Cell 81:525-531.

Zinsmaier KE, Hofbauer A, Heimbeck G, Pflugfelder GO, Buchner S, Buchner E (1990) A cysteine-string protein is expressed in retina and brain of Drosophila. J Neurogenet 7:15-29.

Zito K, Parnas D, Fetter RD, Isacoff EY, Goodman CS (1999) Watching a synapse grow: noninvasive confocal imaging of synaptic growth in Drosophila. Neuron 22:719-729. 